DOI 10.37882/2223-2982.2021.10-2.23

\title{
КУЛЬТУРНОЕ НАСЛЕДНИЕ ГЕРМАНИИ В ПОСЛЕВОЕННЫЙ ПЕРИОД
}

\section{CULTURAL LEGACY OF GERMANY IN THE POSTWAR PERIOD}

N. Kharchenko

A. Chukhina

I. Bagdasarova

N. Lutsenko

Summary: This article is devoted to the cultural heritage of Germany in the postwar period. The architectural aspect and visual arts of German architects and artists are considered. Analyzed the change in the direction of culture after the fall of the Nazi regime.

Keywords: postwar Germany, culture, architecture, visual arts.
Харченко Николай Леонидович

старший преподаватель, Российская академия народного хозяйства и государственной службы при Президенте Российской Федерачии m-rh@mail.ru

Чухина Анастасия Александровна К.и.н., доцент, Северный государственный медицинский университет (Архангельск) chuhina.anastasia@yandex.ru

Багдасарова Илона Юрьевна старший преподаватель, Московский физикотехнический институт (национальный исследовательский университет) artameli@mail.ru

Луценко Наталья Станиславовна старший преподаватель, Московский физикотехнический институт (национальный исследовательский университет) nataly.l@inbox.ru

Аннотация: Данная статья посвящена культурному наследию Германии в послевоенный период. Рассматриваются архитектурный аспект и изобразительное искусство немецких архитекторов и художников. Анализируется изменение направленности культуры после падения нацистского режима.

Ключевые слова: послевоенная Германия, культура, архитектура, изобразительное искусство.

2. Восстановить страну и начать писать её историю заново, развивать культуру дальше

Однако не стоит упускать из внимания тот факт, что Германия была разделена на 2 половины, влияние на которые оказывали ярые политические соперники США, Франция, Англия - с одной стороны и СССР с другой. Поэтому многие произведения послевоенной эпохи также подвергались существенному цензу.

Кинематограф послевоенной Германии не отличался особыми изысками и посвящен был больше документалистике. Как в восточной, так и в западной части страны документальные фильмы снимались по нескольким основным тематическим направлениям:

- восстановление промышленности, городов и инфраструктуры

- порицание фашистского режима

- современная политическая пропаганда (в ФРГ и ГДР большое внимание уделялось «идеологической выдержанности» контента, который должен был доходить до потребителя, т. к. ни одна из противоборствующих держава не хотела уступать 
свои позиции в только что приобретённых зонах влияния)

Из творчества документалистов СССР и ГДР того времени стоит отметить такие картины, как: «Демократическая Германия» (Центральная студия документальных фильмов СССР совместно с Германской студией документальных фильмов «ДЕФА»), в котором отражены основные значимые политические события первых послевоенных лет и процессы восстановления промышленности и экономики. Также можно отметить и периодические видеоматериалы под общими названиями «По Берлину» и «Новости Дня», в которых ведётся летопись восстановления и отражения быта простых немецких граждан [3].

Ярких примеров документальных работ того времени в исполнении западных соседей найти, к сожалению, не удалось, но можно предположить, что существенных отличий по содержанию и смысловой нагрузке они в себе не несли.

Немецкие архитекторы того времени обращали свой взор на жертвы фашизма, а также всех тех, кто боролся за права свободной Германии. Одним из наиболее значимых является «Памятник борцам Сопротивления фашизму в Бухенвальде», построенный в период с 1952 по 1958 годы. Архитектором стал Ф. Кремер, почетный член Академии художеств Советского Союза. У основания знаменательной башни-колокольни была установлена скульптурная композиция, которая олицетворяет пленников концлагеря - героев Сопротивления. Эти образы оставлены будущим поколениям в качестве предупреждения обо всех ужасах и тяготах миллионов людей, участвовавших в военных действиях [5, с. 207].

Свержение фашистского режима обозначило для немецкой архитектуры два противоположных направления дальнейшего развития. В Германской Демократической Республике народ, изгнав капиталистов и помещиков, вступил на твердый путь строительства социализма и становления социалистической культуры. Западная часть Германии, ФРГ и Западный Берлин продолжали действовать с капиталистической точки зрения [2].

Художники Германии начинают создавать оптимистичные произведения, среди которых можно выделить работы Макса Лингнера (1888-1959) и Леа Грундиг (19061979). Являясь противниками фашизма, они активно развивали прогрессивную графику. Лингнер является автором одной из самых монументальных росписей, оказавшей влияние на последующее развитие немецкого искусства. Речь идет о двадцатипятиметровом фризе Дома министерства в Берлине. В своем творении «Крестьянская война» (1952-1955) художник сделал уклон на исторические события в Германии. Лингнер смог сотво- рить обобщенный образ значимой для немецких людей эпохи, сочетая эмоциональный диссонанс и реальные исторические события в ярко выраженной форме.

Немецкий художник Отто Нагель (1894-1967) организовал Выставку немецкого искусства в СССР в 19241925 годах. Он принимал активное участие в совместной работе с коммунистами. Являясь одним из основоположников укрепления дружественных контактов с художниками Советского Союза в 1920-е годы, Нагель получил звание почетного члена Академии художеств СССР. Его произведения «Новая учительница» и «Молодой строитель-каменщик» отражают образы трудового народа свободной от фашизма Германии с просветленными открытыми лицами, уверенными в будущем взглядами. В работах художника Рудольфа Бергандера (1909-1970) ведущую роль занимает тема современности. Он создал несколько связанных общей мыслью произведений, используя новаторские и довольно смелые идеи [6, с. 132]. В качестве натурщиц для его картин выступили обнаженные свободные женщины Восточной Германии. На жизнерадостных картинах Вальтера Вомака - характерные черты быта и трудовой жизни народа Восточной Германии. Его работами являются: «Сборщицы свёклы» (1956) «Девочка с голубем» (1957), «На пляже» (1962).

Считаю, что отдельное внимание стоит уделить архитектуре послевоенной Германии, так как именно в этой области деятельность велась активнее всего (что неудивительно, ведь большая часть страны была разрушена).

Благоприятная экономическая обстановка, которая сложилась в пятидесятые годы, опиралась на приток денежных средств из Соединенных Штатов, что оказало существенное влияние на подвижки в строительстве. Больше всего внимания уделялось инфраструктурным и промышленным объектам. Архитекторы ФРГ добились весомых успехов в этом направлении в послевоенное время, проектируя и создавая оригинальные сооружения.

В 1953 г. был построен четырехэтажный гараж в Дюссельдорфе. Главным архитектором и создателем проекта стал Шнайдер-Эслебен, который подарил Западной Германии одно из наиболее значительных архитектурных зданий того времени.

Сооруженная в период с 1954 по 1956 годы телебашня в Штутгарте, архитектором которой является Фриц Леонардт, стала живым прототипом для будущих телевизионных станций в некоторых странах. Ее конструкция представляет собой бетонный ствол формы конуса, внутри которого размещены подъемные лифты и лестница. На высоте 136 м башня была дополнена шестиярусной надстройкой, в которой располагались службы технического контроля, ресторан в два этажа и пара смотровых площадок. Завершала конструкцию укрепленная метал- 
лическая мачта высотой 51 м. С виду напоминает останкинскую телебашню.

Оригинально и с изяществом был сконструирован мост Святого Северина в Кельне (1957-1960), архитектором которого стал Г. Ломер. Полотно сооружения решили подвесить на вантах к единственной центровой опоре высотой 85 метров.

Существенная нехватка жилья в Германии требовала чрезвычайных мер, поэтому правительство было вынуждено направить средства в отрасль строительства жилья для населения. Показатели масштаба развития данного направления с середины 50-х годов вывели страну на одно из первых мест в капиталистическом мире. Стоит отметить, что качество проводимых работ в разы уступало их объему. Строительство жилых зданий в послевоенное время не помогло внести новые идеи в развитие жилищного комплекса и типологии домов в ФРГ.

Активизация строительства в этом направлении рассматривалась только как неизбежный компонент для восстановления промышленных возможностей страны. Данный процесс был искусственно ускорен за счет необходимости наращивания жилого фонда. Острая нехватка жилья позволяла строительным организациям не слишком переживать за качество возводимых домов. В предельно сжатые временные рамки построили максимально возможное количество трех- и пятиэтажных секционных домов с ограниченной планировкой жилых помещений, в большинстве случаев лишенных стандартного комплекса бытовых удобств. Как и следовало ожидать, Германия достигла первоначальной цели и обогатила жилой фонд. Однако большая часть зданий уже в 60-е годы устарела с технической стороны и требовала замены.

Следует упомянуть о Гансе Шаруне, который считается самым ярким представителем «органической архитектуры» в ФРГ. Огромную роль он сыграл в проектировании театральных и концертных залов, на строительство которых направлялись немалые ресурсы. В 1952 г. Шарун принимает участие в конкурсе проектов на возведение театра в Мангейме, в процессе чего создает оригинальную композицию здания. Сложные криволинейные формы никак не сочетались с программой двухзального театра. В начале 50-х годов, когда немецкие архитекторы стремились возродить традиции функционализма, смелый проект Шаруна не получил признания. Однако впоследствии влияние творчества архитектора, затейливо сочетающего устойчивые традиции «биологического функционализма» и экспрессионизма двадцатых годов с веяниями «органической архитектуры», можно встретить в работах многих архитекторов. Это касается и обновленных театрально-концертных зданий (в част- ности, в Мюнстере и Штутгарте). Близка к проекту театра в Мангейме и работа Шаруна по модернизации театра в Касселе.

Вторая половина 50-х годов характеризуется усилением иррационалистических направлений в архитектуре ФРГ и Западного Берлина. Это наглядно увидели уже по итогам конкурса 1957 г. на проект концертного зала для филармонии в Западном Берлине: первую премию получил именно Шарун. А ведь именно он и создал проект, по которому это здание было выстроено. Согласно объемно-пространственной композиции концертный зал представляет собой трудно планируемое сооружение, где нередко встречаются изломы, выступы, резкие грани спонтанные углубления. Данный проект Шаруна благодушно восприняли архитектурные критики и сделали его неким знаменем иррационализма в немецкой архитектуре конца 50-60-х гг.

Понимание и отражение в архитектуре ФРГ нашла укрепившая позиции в США техническая ветвь функционализма (школа Мис ван дер Роэ), связанная с возведением корпоративных офисных зданий. Сооружения из стекла массово разрастались в 50-е годы во многих городах ФРГ.

Определенную роль архитектура США оказала и на строительство таких сооружений, как здания атомных реакторов. К примеру, основанное на проекте Г. Вебера в Гархинге здание атомного реактора в 1957 г. имеет много схожих черт с аналогичной постройкой, возведенной несколькими годами ранее в американском Плейнсборо. Объект в Гархинге получил форму вытянутого эллипсоидального купола (диаметром и высотой 30 м), выполняющего функцию целостной железобетонной десятисантиметровой защиты. Наружная часть купола покрыта листами из прочного алюминиевого сплава.

В Восточной Германии в 60-е создаются ансамбли, решающие проблему интеграции современных течений в только что восстановившуюся после войны культурную жизнь Германии. В качестве примера можно привести фреску, созданную Герхардтом Бондцином на фасаде здания Дворца культуры в Дрездене, а также Университет имени Гумбольдта в Берлине.

К 70-м годам, благодаря активному росту экономики и промышленности, культура германии начинает идти по современному пути развития и окончательно освобождается от пережитков прошлого после падения Берлинской стены. Хочется отметить, что, несмотря на годы правления фашистского режима, несколько лет войны, раздробленность страны в послевоенный период, Германия всё же не потеряла присущий ей колорит, а также сумела перенять основные культурные ценности немецкого народа. 


\section{ЛИТЕРАТУРА}

1. Иванова Е.А. “Медийная культура Германии” как новый спецкурс в профессиональном языковом образовании // Педагогическое образование в России. 2014. № 6. С. 105-108.

2. Корнева Л.Н. Наука и культура в нацистской Германии в оценке германских историков // Вестник Кемеровского государственного университета. 2012. № 1. T. 4. 4-1 (52). C. 57-62.

3. Советская военная администрация в Германии 1945-1949 гг. Политика СВАГ в области культуры, науки и образования: цели, методы, результаты // Сб. док. / под ред.: Х. Меллера и А.0. Чубарьяна. - М.: РОССПЭН, 2006. - 976 с.

4. Усов, С.С. Эмоционально-оценочная номинация реалий в политическом дискурсе в XXI в / С.С. Усов, М.А. Сафонов, Н.Л. Харченко // Известия Волгоградского государственного педагогического университета. - 2020. - № 3(146). - С. 105-109.

5. Trufanov, G.A. Governmental control over information distribution as a basis of the social conflict / G.A. Trufanov // Конфликтология. - 2019. - Vol. 14. - № 3. P. 207-221.

6. Trufanov, G.A. Crisis and conflict in Russian contemporary social media / G.A. Trufanov // Конфликтология. - 2021. - Vol. 16. - № 1. - P. $132-158$.

( ) Харченко Николай Леонидович (m-rh@mail.ru), Чухина Анастасия Александровна (chuhina.anastasia@yandex.ru),

Багдасарова Илона Юрьевна (artameli@mail.ru), Луценко Наталья Станиславовна (nataly.!@inbox.ru).

Журнал «Современная наука: актуальные проблемы теории и практики»

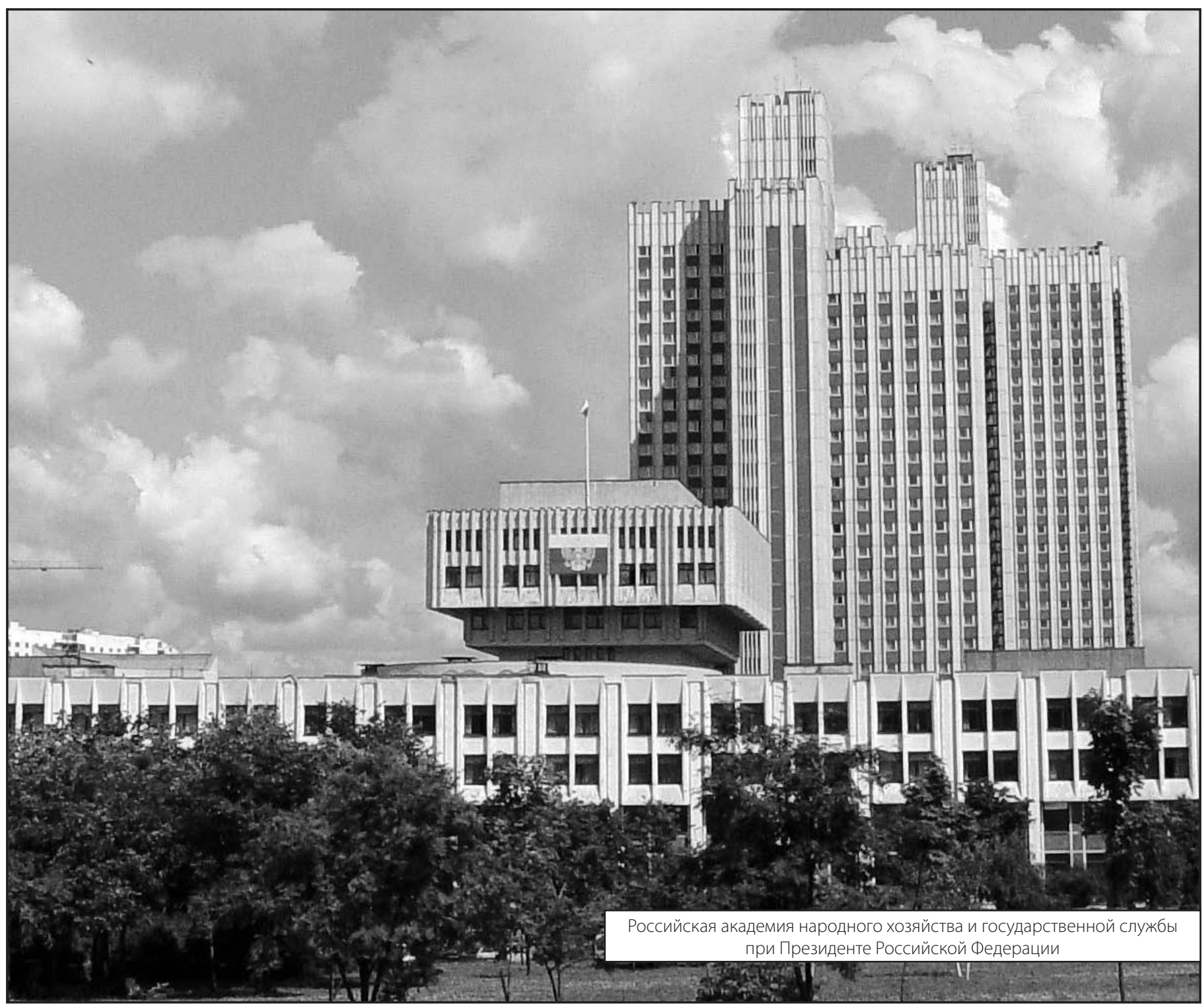

